\title{
Autonomy and Relatedness Satisfaction Predicting Psychological Well-Being of Adolescents: Focusing on Individualism- Collectivism Cultural Values
}

\author{
Seungbin Hong, Seong Yeon Park \\ Department of Child Development \& Intervention, Ewha Womans University, Seoul, Korea \\ 청소년의 자율성 및 관계성 만족이 심리적 안녕감에 미치는 영향: 개인 \\ 주의-집합주의 가치관에 따른 차이 \\ 홍승빈, 박성연 \\ 이화여자대학교 아동학과
}

Objective: The purpose of this study was to examine the moderating role of cultural values in the associations between autonomy and relatedness satisfaction of adolescents on their psychological well-being

Methods: A total of 506 high school students $(M$ age $=16.2)$ in Korea completed self-reported measures of needs satisfaction, psychological well-being, and cultural values, and data were analyzed by Pearson's correlation and hierarchical multiple regression analyses.

Results: The results were as follows: First, both autonomy and relatedness satisfaction were positively related to adolescents' well-being. Second, Collectivistic-Individualistic value moderated the associations. Especially, only for collectivism oriented adolescents, the positive effect of autonomy satisfaction on psychological well-being was significant when their relatedness satisfaction was high.

Conclusion: The findings suggest the importance of both autonomy and relatedness satisfaction in predicting psychological well-being of adolescents and underscore the moderating role of cultural values.

Keywords: adolescents, autonomy-satisfaction, relatedness-satisfaction, psychological well-being, individualism-collectivism cultural values

\begin{abstract}
서론
청소년기에는 발달적으로 신체적, 인지적, 심리적으로 급격한 변화를 경험하고, 다양한 발달과업 수행이 요구되면서 심리적 스트레스가 증가하게 된다. 특히, 우리나라 청소년은 중·고등

Corresponding Author: Seung bin Hong, Department of Child Development \& Intervention, Ewha Womans University, 52, Ewhayeodaegil, Seodaemun-gu, Seoul 03760, Korea

E-mail: bin850118@naver.com
\end{abstract}

학교시기에 들어서면서 학교 환경이 보다 경쟁 지향적으로 변 화하고, 학업에 대한 집중이 강요됨에 따라 더 많은 스트레스 와 갈등을 경험하면서 심리적 안녕감에 위협을 받게 된다. 이 러한 현실을 반영하듯, 2006년 Organisation for Economic Cooperation and Development $(\mathrm{OECD})$ 가 실시한 각국의 청소년

(C)The Korean Association of Child Studies

This is an Open Access article distributed under the terms of the Creative Commons Attribution Non-Commercial License (http:// creativecommons.org/licenses/by-nc/4.0) which permits unrestricted noncommercial use, distribution, and reproduction in any medium, provided the original work is properly cited. 
을 대상으로 한 삶의 만족도 조사에서 핀란드는 $81.6 \%$, 미국 은 78.3\%의 청소년이 행복하다고 응답한 반면, 우리나라 청소 년(15-24세)은 44.9\%가 행복하다고 응답하여, 7개국 중 최하 위를 나타냈다(National Youth Policy Institute, 2010). 이러한 청 소년의 낮은 심리적 안녕감은 개인의 행복이나 학교적응은 물 론, 비행이나 자살 등 여러 가지 사회적인 행동 문제를 야기하 기 때문에(Kang, 2010; A. Kim \& Lee, 2008), 청소년의 심리적 안녕감을 예측해 주는 변인들이 무엇인지를 파악하는 일은 중 요하다.

Ryan과 Deci (2000)에 의해 주장된 자기결정이론(SelfDetermination Theory [SDT])에 의하면, 인간은 기본적으로 자 율성(autonomy), 관계성(relatedness) 및 유능성(competence)의 세 가지 심리적 욕구를 가지고 있으며, 이러한 보편적인 세 가 지 욕구의 충족은 심리적 안녕감에 영향을 미치는 중요변인으 로 가정된다. 자율성은 외부의 통제를 받지 않고 자신의 의지 에 따라 자발적으로 결정하고 행동하는 것을 의미하며(Ryan $\&$ Deci, 2000), 관계성은 타인과의 결속감(connectedness)이나 소속감을 뜻한다(Ryan \& Deci, 2002). 인간은 누구나 자율성을 발휘하려는 유기체적 성향을 지니고 태어나므로, 자신의 의지 에 따라 하고자 하는 행동을 실행하려는 것은 자연스럽고 보 편적인 경향이다. 또한 사회적 동물인 인간은 타인과의 친밀 한 관계를 통해 수용되는 심리적 느낌을 얻고자 하는 관계성 의 욕구를 충족하고자 한다. 특히 자율성과 관계성 욕구는 인 간의 긍정적 기능을 촉진하기 위한 필수적인 욕구이자, 두 욕 구가 사회적 맥락이나 대인관계에서 지지될 때, 유능함을 느 끼게 되고 심리적 안녕감은 증대된다(Chirkov, Ryan, Kim, \& Kaplan, 2003; Jeon, Sihn, \& Yoo, 2011; E. J. Kim, 2007; S. Lee, 2009; Levesuque, Zuehlke, Stanek, \& Ryan, 2004).

자율성 만족 및 관계성 만족과 심리적 안녕감 간의 정적인 관련성은 많은 국내외 연구들에서 지지되고 있다. 예를 들어, 다른 사람과의 관계에서 자율성 만족을 경험하는 청소년들은 주관적 안녕감이 높고(Chirkov \& Ryan, 2001; Lynch, 2010), 부 모나 교사로부터 자율성 지지를 경험한 중학생은 심리적 안녕 감이 높다(Ahn, Park, \& Jung, 2008). 또한 관계성 만족 정도가 높을수록 긍정적 정서를 많이 경험하고 심리적 안녕감이 높 으며(Sheldon, Elliot, Kim, \& Kasser, 2001; Veronneau, Koestner, \& Abela, 2005), 관계성 만족을 높게 지각하는 학생일수록 학 교생활에 적응을 더 잘하고, 삶에 대한 만족도가 더 높은 것으 로 보고되고 있다(E. J. Kim, 2007; S. Lee, 2009; Shin, 2011). 따 라서 자율성과 관계성의 욕구 모두 청소년의 심리적 안녕감에 특히 중요한 요소임을 알 수 있다.
한편, 자율성과 관계성이 보편적인 인간의 욕구로서 문화 적 특성과 관계없이 개인의 심리적 안녕감과 정적으로 관련 된다는 SDT 관점(Petegem, Beyers, Vansteenkiste, \& Soenens, 2011; Vansteenkiste, Lens, Soenens, \& Luyckx, 2006)과 달리, 문 화적 상대주의 입장을 취하는 학자들은 이러한 심리적 욕구의 만족이 심리적 안녕감에 미치는 영향은 문화에 따라 다를 수 있다는 문화적 특수성을 주장한다(Markus \& Kitayama, 2003; Oishi, 2000). 이들에 의하면, 개인적 가치나 자율성, 유능감이 더욱 강조되는 개인주의 사회와 달리 조화와 화합을 강조하 는 집합주의 사회에서는 자율성을 추구하는 것은 오히려 개인 의 안녕감 증진을 방해하는 요인으로 작용한다고 본다. 즉 관 계성과 자율성의 욕구(needs)는 공존할 수 없기 때문에, 자율 성이 만족되면 관계성 만족은 낮아지는 한편, 관계성 만족이 이루어지면 자율성 만족이 낮아지게 되므로 두 욕구의 양립은 내적 긴장을 유발하여 궁극적으로 안녕감을 저해한다고 주장 한다(Cross \& Gore, 2003; Rudy \& Grusec, 2001).

이렇듯 SDT 관점과 문화적 상대주의 입장에서의 상반 된 주장은 자율성에 대한 개념의 차이에 기인하기도 한다 (Vansteenkiste et al., 2006). 즉, 자기결정이론에 자율성의 개념은 자신의 의지에 의한 자발적인 행동으로 정의하는 반면, 비교문 화적 입장에서는 자율성을 독립 또는 분리의 개념으로 이해한 다. 따라서 자기결정이론의 바탕을 둔 자율성의 개념을 적용한 다면 자율성과 관계성의 욕구는 문화보편적 특성이며, 이 두 욕 구의 충족은 심리적 안녕감에 긍정적인 영향을 미칠 것으로 가 정된다. 지금까지의 많은 연구들에서 자율성과 관계성의 욕구 는 서로 긍정적인 상관이 있으며(La Guardia, Ryan, Couchman, \& Deci, 2000; Soenens \& Vansteenkiste, 2005), 이 두 요소는 서구 에서는 물론 한국을 비롯한 아시아권 문화에서도 개인의 심리 적 안녕감과 긍정적인 관련이 있음이 보고되고 있다(Deci et al., 2001; Sheldon et al., 2001; Vansteenkiste et al., 2006).

그럼에도 불구하고 인간의 보편적 욕구인 자율성과 관계성 은 문화적 가치관에 따라 두 욕구의 만족이 심리적 안녕감에 미치는 상대적 영향력의 크기가 다를 수 있다. 일반적으로 독 립성, 분리, 독립된 자아 같은 특성을 강조하는 개인주의 사회 에서는 타인과 독립되는 자기관을 형성하는 반면, 관계와 조 화를 중시하는 집합주의 사회에서는 타인과의 관계를 바탕으 로 하는 자기관을 형성하게 된다(Kitayama \& Markus, 1998). 이러한 입장에서 보면, 개인주의 사회에서는 자율성 만족이 개인의 심리적 안녕감에 더 큰 영향력을 보일 것이고 이에 반 해, 집합주의 사회에서는 관계성 만족의 영향력이 더 클 것으 로 가정된다. 이를 뒷받침하는 증거로 국내외 몇몇 연구에서 
는 자율성과 관계성 만족이 심리적 안녕감에 미치는 영향은 문화적 가치관에 따라 달라질 수 있음을 시사하고 있다. 예를 들어 비교문화연구 결과, 자율성과 관계성 만족이 모두 심리 적 안녕감과 정적인 관련이 있으나, 미국대학생은 자율성 욕 구가 심리적 안녕감에 더 큰 영향력을 미치는 변인으로 나타 난 반면, 한국대학생은 관계성의 욕구가 자율성 욕구보다 심 리적 안녕감에 더 큰 영향력을 나타냈다(Sheldon et al., 2001). 국내 연구에서 역시 관계성의 욕구가 자율성의 욕구 보다 청 소년이나 대학생의 심리적 안녕감에 더 큰 영향력을 미치는 것으로 보고되고 있다(Han \& Shin, 2009; E. J. Kim, 2007; S. Lee, 2009). 유사한 맥락에서 Jeon 등(2011)은 자율성 만족이 심 리적 안녕감에 직접적인 영향을 미치지 않는 대신 관계성 만 족에 영향을 줌으로써 안녕감에 영향을 미친다고 보고하여 관 계성 만족의 중요성을 강조한바 있다. 한편, 자율성 만족과 관 계성 만족이 심리적 안녕감에 미치는 영향력은 문화적 가치관 뿐 아니라 개인이 처한 상황에 따라 달라질 수 있음을 시사하 는 연구도 있다. Vansteenkiste 등(2006)에 의하면, 중국 대학생 들은 관계성과 자율성을 모두 만족했을 때 높은 심리적 안녕 감을 보였으나, 중국에 사는 중국대학생과 달리 벨기에에 체 류 중인 중국대학생은 관계성 만족을 낮게 지각하더라도 자율 성 만족을 높게 지각할 경우에는 더 높은 활력감(vitality)을 느 끼는 것으로 나타났다.

종합하면, 대체로 문화보편적인 욕구인 자율성과 관계성 욕구의 만족은 인간의 심리적 안녕감에 긍정적인 영향을 미 치는 요인임이 입증되고 있는 한편, 문화적 가치관에 따라 또 는 개인이 처한 상황에 따라 자율성과 관계성 만족의 영향력 의 상대적 크기가 다를 수 있다는 것이 시사되고 있다. 이에 본 연구에서는 한국 청소년들의 자율성 만족 및 관계성 만족 과 심리적 안녕감 간의 관계를 파악하는데 있어 문화적 가치 관의 영향을 고려하고자 한다. 특히 같은 문화권 내에서도 개 인주의와 집합주의 가치관이 공존할 수 있음(Kagitcibasi, 2005; Park, 2012)에도 불구하고, 우리나라 청소년들의 문화적 가치 관을 개인주의와 집합주의 가치관 두 측면을 고려하여 자율성 및 관계성 만족과 심리적 안녕감 간의 관계를 살펴본 연구는 찾아보기 힘들다. 이에 본 연구에서는 고등학생 청소년을 대 상으로 자율성 만족 및 관계성 만족이 심리적 안녕감에 미치 는 상대적 영향력을 살펴보는 한편, 청소년이 지닌 개인주의집합주의 가치관 지향 정도에 따라 자율성 및 관계성 만족이 심리적 안녕감에 미치는 영향에 차이가 있는지를 규명하는데 연구의 목적을 두고자 한다. 본 연구에서 설정한 연구문제는 다음과 같다.

\section{연구문제 1}

청소년의 자율성 및 관계성 만족이 심리적 안녕감에 미치는 상대적 영향력은 어떠한가?

\section{연구문제 2}

청소년의 자율성 및 관계성 만족이 심리적 안녕감에 미치는 영향은 개인주의-집합주의 가치관에 따라 차이가 있는가?

\section{연구방법}

\section{연구대상}

본 연구대상은 수도권 및 대전 지역 인문계 고등학교에 재학 중인 1,2학년 학생 506명(남: 228명; 여: 278명)으로 평균연령 은 $16.2(S D=0.44)$ 세이다. 연구대상 청소년들의 아버지의 약 $82 \%$ 와 어머니의 약 $71 \%$ 가 전문대 졸업이상의 교육수준을 보 였으며, 청소년이 지각한 사회경제적 수준은 약 $80 \%$ 가 ‘중’ 이 상으로 나타나, 연구대상 청소년의 가정은 중류가정으로 볼 수 있다.

\section{조사도구}

본 연구의 연구문제 분석을 위하여 사용된 측정도구는 청소년 의 자율성 및 관계성 만족, 개인주의-집합주의 가치관 및 심리 적 안녕감에 관한 질문지 척도로 구성되어 있으며, 모든 척도 는 청소년 자기보고용이다.

\section{청소년의 자율성 및 관계성 만족척도}

청소년의 자율성 및 관계성 만족을 측정하기 위해 Deci와 Ryan $(2000,2002)$ 이 개발한 기본 심리적 욕구 척도(Basic Psychological Needs Scale [BPNS])를 M. Lee와 Kim (2008)이 청 소년을 대상으로 개발 및 타당화한 한국형 기본 심리적 욕구 척도 중 자율성과 관계성 하위척도를 선택하여 사용하였다. 자율성과 관계성 만족 원 척도는 각각 6 문항으로 이루어져 있 으며, 자율성 만족 문항은 "나는 다른 사람들에 의해 통제받고 억압을 받는다고 느낀다.", "나는 대체로 내 생각과 의견을 자 유롭게 표현할 수 있다고 느낀다.”를 예로 들 수 있다. 관계성 문항의 예로는 "나는 내 주변 사람들로부터 사랑과 관심을 받 는 것을 느낀다.", "내 주변 사람들은 평소에 나와 감정을 공유 
할 때가 많다.” 등이다. 원래 각 문항은 Likert식 6점 척도로 되 어 있으나, 본 연구에서는 전혀 그렇지 않다(1점)에서 매우 그 렇다(5점)의 Likert식 5점 척도로 바꾸어 사용하였으며, 문항 에 따라 역 코딩하여 점수가 높을수록 청소년이 지각한 자율 성과 관계성 만족이 높음을 의미한다. 본 연구에서 자율성 만 족 및 관계성 만족 척도의 내적 신뢰도는 각각 $\alpha=.79, \alpha=.83$ 으로 나타났다.

\section{청소년의 개인주의-집합주의 가치관}

청소년의 개인주의-집합주의 가치관을 측정하기 위해 Triandis (1995)가 제작한 주관적 개인주의-집합주의 성향 척도 (Subjective Individualism and Collectivism [SINDCOL])를 Cha (1999)가 요인분석을 통해 수정, 보완한 28개 문항을 사용하 였다. 개인주의 가치관을 나타내는 문항(13개)의 예로는 "나 에게 일어난 일은 내 자신이 한 행동 때문이다.", "나만의 개 인 생활을 좋아한다." 등의 내용을 들 수 있으며, 집합주의 가 치관 문항(15개)의 예로는 "내가 속한 집단과 조화를 유지하 는 것이 나에게 중요한 일이다.", "다른 사람들과 함께 시간을 보내는 것은 나의 즐거움이다." 등이 있다. 본 척도의 응답 방 식은 전혀 동의하지 않는다(1점)에서 매우 동의한다(5점)의 Likert식 5점 척도로, 점수가 높을수록 개인주의 또는 집합주 의 가치관이 높은 것을 의미한다. 본 연구에서 개인주의-집합 주의 가치관 척도의 신뢰도는 개인주의 가치관이 $\alpha=.74$, 집 합주의 가치관이 $\alpha=.78$ 로 나타났다.

\section{청소년의 심리적 안녕감}

청소년의 심리적 안녕감은 Ryff와 Keyes (1995)가 제작한 심리 적 안녕감 척도(Psychological Well Being Scale [PWBS])를 Park (2007)이 다소 수정, 보완한 척도를 사용하였다. PWBS는 자율 성, 환경통제력, 개인적 성장, 타인과의 긍정적 관계, 삶의 목 적, 자기수용의 6개 하위 영역에 각 3문항 씩, 총 18 문항으로 구성되어 있으며, 자신의 삶의 여러 영역에서 정서적으로 느 끼고 인지하는 안녕감의 수준을 나타낸다. 심리적 안녕감 척 도의 문항 예로는, "나는 여러 가지 일상적인 일들을 꽤 잘 수 행해 나간다.", "어떤 사람들은 삶의 목적이 없이 방황하지만 나는 그렇지 않다.", "나는 자신이나 세상에 대한 내 생각에 도 전하는 새로운 경험을 가지는 것이 중요하다고 생각한다.” 등 이 포함된다.

원 척도의 문항은 전혀 동의하지 않는다(1점)에서 매우 동
의한다(7점)의 Likert식 7점 척도이나, 본 연구에서는 전혀 동 의하지 않는다(1점)에서 매우 동의한다(5점)의 Likert식 5점 척 도로 수정하였으며, 점수가 높을수록 안녕감이 높음을 의미한 다. 본 연구에서 심리적 안녕감 18 개 문항의 내적 신뢰도는 $\alpha$ $=.78$ 로 나타났다.

\section{조사절차 및 자료분석}

자료수집을 위해서는 수도권 및 대전 지역에 위치한 고등학 교 중 해당 학교장의 허락을 얻은 3 개 학교를 방문하여 담임교 사를 통해 질문지를 배부하였다. 총 720 부의 질문지를 배부하 여 약 580 부(회수율 약 $81 \%$ )가 회수되었으나 이 중 불성실하 게 응답한 경우(74부)를 제외하고 총 506부의 질문지만을 분석 에 사용하였다. 자료분석을 위해서는 Pearson 상관관계 분석, Fisher's $z$-test 및 위계적 회귀분석을 실시하였다. 연구문제 1을 위한 위계적 회귀분석 시 1 단계에서 통제변인인 청소년의 성 을 투입하였으며, 2 단계에서는 독립변인인 자율성과 관계성 만족을, 3 단계에서는 자율성과 관계성 만족의 상호작용 변인 을 투입하여 종속변인인 심리적 안녕감에 미치는 영향을 살펴 보았다. 한편 개인주의-집합주의 가치관의 중재역할을 알아보 기 위한 연구문제 2 를 위해서는 개인주의 가치관 집단과 집합 주의 가치관 집단으로 구분하여 성을 통제한 위계적 회귀분석 을 실시하였다. 집단구분 시, 개인주의 및 집합주의 점수 각각 의 상위 $33.3 \%$ 를 기준으로 하여 개인주의 점수가 높은 개인주 의 가치관 집단과 집합주의 점수가 높은 집합주의 가치관 집단 으로 나누었다. 이 과정에서 개인주의 점수와 집합주의 점수가 모두 상위 $33.3 \%$ 에 해당할 경우는 집단에서 제외하였다.

\section{연구결과}

\section{연구변인들 간의 상관관계}

연구문제 분석에 앞서, 기초분석으로 청소년의 성을 포함하여 측정변인들 간 상관관계를 분석한 결과, Table 1 에서 보듯이 청소년의 자율성과 관계성 만족은 유의미한 정적 상관을 나타 내 $(r=.49, p<.001)$, 자율성 만족이 높은 청소년이 관계성 만 족도 높은 것으로 나타났다. 또한 자율성 만족은 집합주의 점 수 $(r=.14, p<.01)$ 보다 개인주의 점수 $(r=.28, p<.001)$ 와 유의 미하게 더 높은 상관을 $(z=2.33, p<.01)$, 관계성만족은 개인주 의 점수 $(r=.31, p<.001)$ 보다 집합주의 점수 $(r=.47, p<.001)$ 
Table 1

Intercorrelations Among Variables

\begin{tabular}{lcccccc}
\hline & 1 & 2 & 3 & 4 & 5 & 6 \\
\hline 1. Gender & - & & & & & \\
2. Autonomy satisfaction (A) & $.10^{*}$ & - & & & & \\
3. Relatedness satisfaction (R) & $.11^{*}$ & $.49^{* * *}$ & - & & & \\
4. Individualism & $.10^{*}$ & $.28^{* * *}$ & $.31^{* * *}$ & - & & - \\
5. Collectivism & .03 & $.14^{* *}$ & $.47^{* * *}$ & $.28^{* * *}$ & - & $.34^{* * *}$ \\
6. Psychological well-being & -.02 & $.59^{* * *}$ & $.64^{* * *}$ & $.35^{* * *}$ & 3.29 \\
\hline$M$ & - & 3.49 & 3.68 & 3.51 & 3.43 & 0.41 \\
\hline$S$
\end{tabular}

Note. $N=506$. gender: $0=$ boy; $1=$ girl.

${ }^{*} p<.05 .{ }^{* *} p<.01 .{ }^{* * *} p<.001$.

와 유의미하게 더 높은 상관을 보였다 $(z=3.01, p<.01)$. 한편, 자율성 만족과 관계성 만족은 심리적 안녕감과 정적 상관을 보여, 자율성 만족과 관계성 만족이 높을수록 심리적 안녕감 이 높은 것으로 나타났다.

\section{청소년의 자율성 및 관계성 만족이 심리적 안녕감에 미치는 영향력}

연구문제 1 인 청소년의 자율성 및 관계성 만족이 심리적 안녕 감에 미치는 영향을 살펴보기 위해, 위계적 회귀분석을 실시 하였다(Table 2). 위계적 회귀분석에 앞서 독립변인들 간의 공 선선 여부를 확인한 결과 공차한계 값이 .76 1.00, 분산팽창 요인 값이 1 에 근접하여 $(1.000 \sim 1.321)$ 다중공선성의 위험이 없는 것으로 나타났다. 이에 1 단계에서는 청소년의 성을 투입 하였으며, 2 단계에서는 자율성과 관계성 만족 각 변인을, 3 단 계에서는 자율성과 관계성 만족의 상호작용 항을 투입하였다. 그 결과, 통제변인인 청소년의 성은 심리적 안녕감에 대해 유 의미한 영향을 미치지 않았다. 그러나 독립변인인 자율성 만 족과 관계성 만족의 독립적 영향을 추가로 투입한 2 단계에서 는 성의 영향력이 유의하였으며 $(\beta=-.10, p<.01)$, 관계성 만 족 $(\beta=.47, p<.001)$, 자율성 만족 $(\beta=.38, p<.01)$ 의 순으로 심 리적 안녕감에 영향을 미치는 것으로 나타났다. 한편, 자율성 만족과 관계성 만족의 상호작용 변인을 투입한 3 단계에서 성 은 여전히 심리적 안녕감에 대한 부적인 영향을 미쳤으며 $(\beta=$ $-.10, p<.001)$, 관계성 $(\beta=.48, p<.001)$ 과 자율성 만족 $(\beta=.37$, $p$ <.001) 순으로 주 효과와 함께 자율성과 관계성 만족의 상호 작용 효과가 나타났다 $(\beta=.11, p<.001)$. 이에 사후검증을 위
해 Aiken과 West (1991)의 제안에 따라 관계성 만족을 centering 한 평균을 중심으로 $\pm 1 S D$ (상 - 하)집단으로 나눈 후, 집단의 회 귀식 기울기에 대해 유의도를 검증한 결과, 특히 자율성 만족 이 심리적 안녕감에 미치는 영향은 관계성 만족이 낮을 때 $(\beta=$ $.17, p<.001)$ 에 비해 관계성 만족이 높을 때 $(\beta=.29, p<.001)$ 큰 것으로 나타났다(Figure 1). 한편, 회귀식에 포함된 모든 변 인들은 심리적 안녕감 변량의 $53 \%$ 를 설명하는 것으로 나타났 다.

\section{청소년의 자율성 및 관계성 만족이 심리적 안녕감에 미치는 영향력에서 개인주의-집합 주의 가치관에 따른 차이}

연구문제 2 인 청소년의 개인주의-집합주의 가치관의 중재효 과를 살펴보기 위해 개인주의 가치관 집단과 집합주의 가치관 집단 각각을 대상으로 심리적 안녕감에 대한 자율성과 관계성 의 위계적 회귀분석을 실시하였다. 위계적 회귀분석을 실시하 기에 앞서 청소년의 문화적 가치관을 구분하기 위해 개인주 의 및 집합주의 점수에서 상위 $33.3 \%$ 인 개인주의 점수(3.69) 와 집합주의 점수(3.60)를 기준으로, 개인주의 점수가 3.69 이 상인 청소년을 개인주의 가치관 집단으로, 집합주의 점수가 3.60 이상인 청소년을 집합주의 가치관 집단으로 선정하였다. 이 과정에서 개인주의 및 집합주의 점수 모두 상위 $33.3 \%$ 내 에 포함되는 청소년은 집단 구분에서 제외되었다. 한편, 개인 주의 가치관 집단 및 집합주의 가치관 집단 각각을 대상으로 다중공선선 여부를 확인한 결과, 공차한계는 . $72 \sim 1.00$, 분산 팽창요인은 $1.000 \sim 1.384$ 로 다중공선성의 위험이 없는 것으 
로 나타났다.

이에 우선 개인주의 집단을 대상으로 한 위계적 회귀분석 결과, Table 3에서 보듯이 청소년의 성은 심리적 안녕감에 부 적인 영향을 미쳤다 $(\beta=-.26, p<.05)$. 한편, 자율성과 관계성 만족의 독립적 영향을 살펴본 2단계에서는 성이 미치는 효과 가 줄어드는 대신 $(\beta=-.18, p<.05)$, 관계성 만족 $(\beta=.45, p<$ $.001)$ 과 자율성 만족 $(\beta=.37, p<.001)$ 의 순으로 심리적 안녕감 에 정적인 영향을 미쳤다. 상호작용변인을 투입한 3 단계에서 역시 성은 여전히 부적 영향을 미쳤으며 $(\beta=-.18, p<.05)$, 관 계성 만족 $(\beta=.45, p<.001)$ 과 자율성 만족 $(\beta=.37, p<.001)$ 의 순으로 정적인 영향을 미쳤다. 그러나 자율성 만족과 관계성 만족의 상호작용효과는 나타나지 않았다. 한편, 성 및 자율성
만족과 관계성 만족은 개인주의 성향 청소년의 심리적 안녕감 변량을 $54 \%$ 설명하는 것으로 나타났다.

한편 집합주의 집단을 대상으로 한 위계적 회귀분석을 결 과(Table 4), 1 단계에서 성은 심리적 안녕감에 대해 유의미한 영향을 미치지 않았으나, 2 단계에서는 성이 심리적 안녕감에 대한 부적인 영향이 있는 것으로 나타났으며 $(\beta=-.15, p<.05)$, 자율성 만족 $(\beta=.45, p<.001)$ 과 관계성 만족 $(\beta=.32, p<.001)$ 의 순으로 심리적 안녕감에 정적인 영향을 미치는 것으로 나 타났다. 또한 상호작용 항을 투입한 3단계에서는 자율성 만족 $(\beta=.43, p<.001)$ 과 관계성 만족 $(\beta=.32, p<.001)$ 의 주 효과와 함께 자율성 만족과 관계성 만족의 상호작용 효과가 나타났다 $(\beta=2.44, p<.01)$.

\section{Table 2}

Hierarchical Regression for Prediction of Adolescents' Psychological Well-Being ( $\beta$ )

\begin{tabular}{lccc}
\hline & Step 1 & Step 2 & Step 3 \\
\hline Gender & -.02 & $-.10^{* *}$ &. $.10^{* *}$ \\
Autonomy satisfaction (A) & & $.38^{* * *}$ & $.37^{* * *}$ \\
Relatedness satisfaction (R) & & $.47^{* * *}$ & $.48^{* * *}$ \\
A $\mathrm{R}$ & & & $.11^{* * *}$ \\
\hline$R^{2}$ & .00 & .52 & .54 \\
Adjusted $R^{2}$ & .00 & .52 & .53 \\
$\Delta R^{2}$ & & .52 & .01 \\
$F$ & .15 & $182.91^{* * *}$ & $144.06^{* * *}$ \\
$(d f)$ & $(1,504)$ & $(3,502)$ & $(4,501)$ \\
\hline
\end{tabular}

Note. $N=506$. gender: $0=$ boy; $1=$ girl.

${ }^{* *} p<.01 .{ }^{* * *} p<.001$.

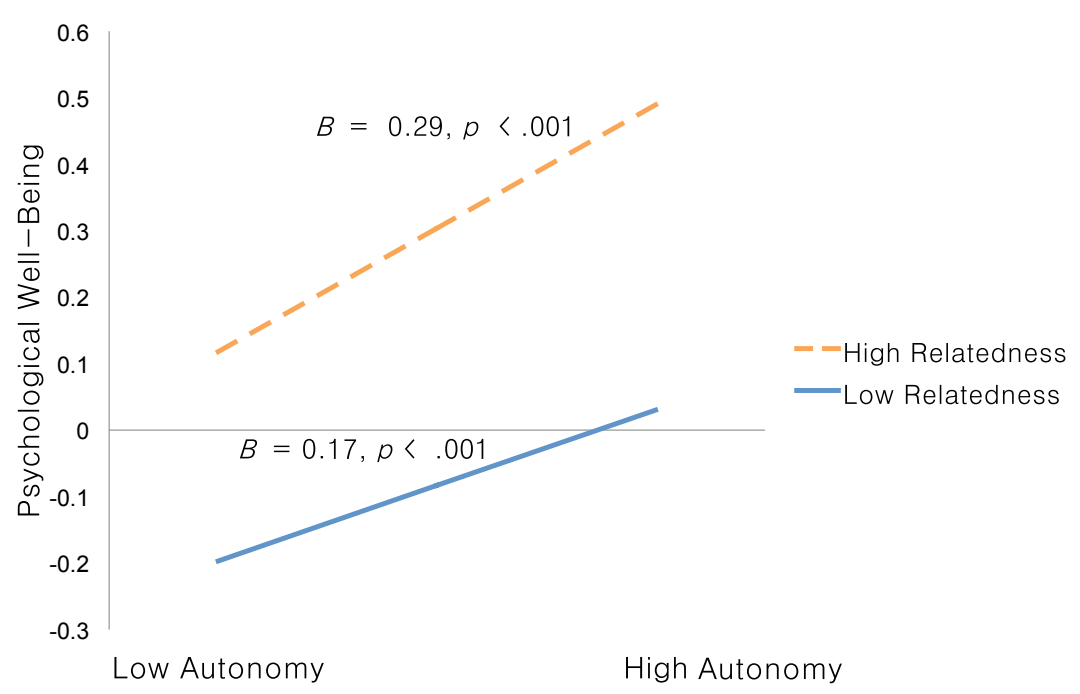

Figure 1. Interaction effect of adolescents' autonomy and relatedness satisfaction on adolescents' psychological well-being. 
Table 3

Adolescents' Autonomy and Relatedness Satisfaction in Predicting the Psychological Well-Being for Individualism-Oriented Adolescents ( $\beta$ )

\begin{tabular}{|c|c|c|c|}
\hline & Step 1 & Step 2 & Step 3 \\
\hline Gender & $-.26^{*}$ & $-.18^{*}$ & $-.18^{*}$ \\
\hline Autonomy satisfaction (A) & & $.37^{* * *}$ & $.37^{* * *}$ \\
\hline Relatedness satisfaction (R) & & $.45^{* * *}$ & $.45^{* * *}$ \\
\hline$A \times R$ & & & .036 \\
\hline$R^{2}$ & .07 & .55 & .55 \\
\hline Adjusted $R^{2}$ & .05 & .54 & .53 \\
\hline$\Delta R^{2}$ & & .48 & .00 \\
\hline$F$ & $5.93^{*}$ & $33.96^{* * *}$ & 25.29 \\
\hline$(d f)$ & $(1,85)$ & $(3,83)$ & $(4,82)$ \\
\hline
\end{tabular}

Note. $N=87$. gender: $0=$ boy; 1 = girl.

${ }^{*} p<.05 .{ }^{* *} p<.01$.

Table 4

Adolescents' Autonomy and Relatedness Satisfaction in Predicting the Psychological Well-Being for Collectivism-Oriented Adolescents ( $\beta$ )

\begin{tabular}{lccc}
\hline & Step 1 & Step 2 & Step 3 \\
\hline Gender & -.09 & $-.15^{*}$ & .13 \\
Autonomy satisfaction (A) & & $.45^{* * *}$ & $.43^{* * *}$ \\
Relatedness satisfaction (R) & & $.32^{* * *}$ & $.32^{* * *}$ \\
A $\times$ R & & & $2.44^{* *}$ \\
$R^{2}$ & .01 & .46 & .51 \\
Adjusted $R^{2}$ & .00 & .45 & .49 \\
$\Delta R^{2}$ & & .45 & .05 \\
$F$ & .77 & $28.90^{* * *}$ & $26.10^{* *}$ \\
$(d f)$ & $(1,102)$ & $(3,100)$ & $(4,99)$ \\
\hline
\end{tabular}

Note. $N=104$. gender: $0=$ boy; 1 = girl.

${ }^{*} p<.05 .{ }^{* *} p<.01 .{ }^{* * *} p<.001$.

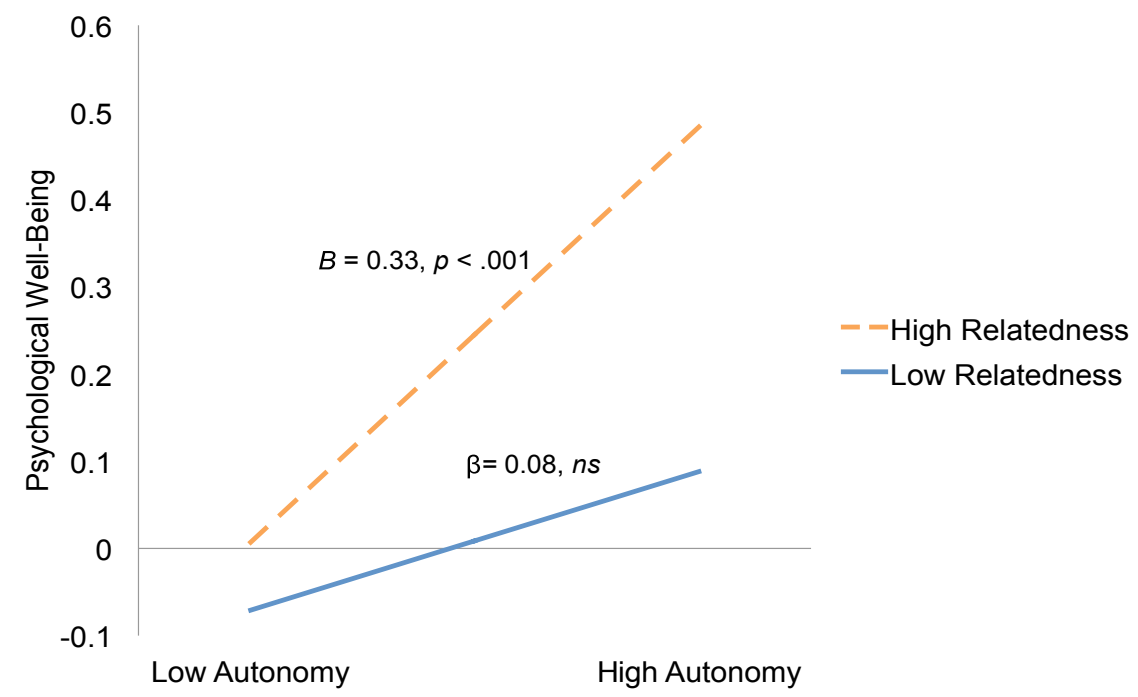

Figure 2. Interaction effect of adolescents' autonomy and relatedness satisfaction on the psychological well-being for collectivismoriented adolescents. 
이를 구체적으로 살펴보기 위해 관계성 만족을 centering한 평균을 중심으로 $\pm 1 S D$ (상.하)집단으로 나눈 후, 집단의 회귀 식 기울기에 대해 유의도를 검증하였다. 그 결과 관계성 만족 이 높은 경우에만 회귀식이 유의한 것으로 나타나 $(\beta=.38, p<$ .001), 관계성 만족이 높은 경우에만 자율성 만족이 심리적 안 녕감에 미치는 긍정적인 영향이 나타났다(Figure 2). 한편 회귀 식에 포함된 모든 변인들은 심리적 안녕감 변량의 $49 \%$ 를 설 명하는 것으로 나타났다.

\section{논의 및 결론}

본 연구는 청소년의 자율성 만족 및 관계성 만족이 이들의 심 리적 안녕감에 미치는 영향을 파악하는 한편, 이러한 영향력 이 이들의 개인주의 또는 집합주의 가치관에 따라 달라지는지 밝히고자 하였다. 본 연구에서 나타난 주요결과를 제시하고 논의하면 다음과 같다.

우선 기초분석으로 전체청소년을 대상으로 변인들 간의 상 관관계를 살펴본 결과, 청소년의 성은 자율성 및 관계성 만족 과 개인주의 점수와 정적 상관을 보여, 여학생이 남학생보다 자율성, 관계성 만족이 높았으며, 개인주의 성향도 높았다. 그 러나 집단주의 성향이나 심리적 안녕감에서는 남녀 간의 차이 가 없었다. 한편, 청소년의 자율성 만족과 관계성 만족은 서로 정적인 관계를 나타내 자율성 만족이 높은 청소년은 관계성 만족이 높은 것으로 나타났다. 또한 청소년이 경험하는 자율 성 만족 및 관계성 만족은 가치관과 정적인 상관을 보여, 자율 성 만족은 특히 개인주의 가치관이 높을 때, 그리고 관계성 만 족은 집합주의 가치관이 높을 때 더 큰 상관을 보였다. 자율성 만족과 관계성 만족 모두 심리적 안녕감과 정적 상관을 보여 두변인 모두 청소년의 심리적 안녕감에 중요한 변인임을 알 수 있다.

한편, 연구문제 1 인 청소년의 자율성 만족 및 관계성 만족 이 심리적 안녕감에 미치는 상대적 영향력을 파악하기 위하여 몇몇 연구변인과 상관을 보였던 성을 통제하고 위계적 회귀분 석을 실시한 결과 첫째, 관계성 만족과 자율성 만족은 각각 독 립적으로 청소년의 심리적 안녕감을 예측하는 것으로 나타났 다. 이러한 결과는 자율성 만족과 관계성 만족의 욕구가 상호 적인 관계이자 양립 가능한 욕구로 보는 자기결정이론의 주장 을 뒷받침하는 것으로(Ryan \& Deci, 2002), 이 두 가지 욕구 충 족이 개인의 심리적 안녕감과 밀접한 관련이 있음을 보고한 선행연구들(Ahn et al., 2008; Chirkov \& Ryan, 2001; A. Kim \&
Lee, 2008; Vansteenkiste et al., 2006; Veronneau et al., 2005)을 지 지한다. 둘째, 상대적 영향력 측면에서 볼 때 관계성 만족이 자 율성 만족보다 한국 청소년의 심리적 안녕감을 더 높게 예측 하는 변인으로 나타났다. 이는 관계성의 욕구가 자율성의 욕 구 보다 한국청소년이나 대학생의 심리적 안녕감에 더 큰 영 향력을 미친다는 국내외 연구(Deci et al., 2001; E. J. Kim, 2007; Han \& Shin, 2009; S. Lee, 2009; Sheldon et al., 2001)들과 일치 한다. 따라서 자율성 만족과 관계성만족이 심리적인 안녕감에 미치는 영향은 개인이 속한 사회의 문화적 가치관에 따라 그 상대적 영향력이 달라질 수 있다는 주장(Kitayama \& Markus, 1998)을 지지한다. 이러한 결과는 우리나라 청소년의 경우 관 계성 만족이 심리적 안녕감에 가장 중요한 변임임을 확인한 대부분의 연구들(E. J. Kim, 2007; S. Lee, 2009, Sheldon et al., 2001)을 지지한다. 셋째, 관계성 만족과 자율성 만족은 서로 상호작용하여 영향을 미치는 것으로 나타났다. 즉, 자율성 만 족이 심리적 안녕감에 미치는 영향은 특히 청소년이 관계성 만족을 높게 경험할 때 가장 크게 나타났다. 이러한 결과는 집 합주의 문화권에서 관계성 만족과 자율성 만족은 공존할 수 없으며, 자율성 만족은 심리적 안녕감을 저해한다는 Cross와 Gore (2003)의 주장에 반하는 것이다. 요약하면 본 연구 결과 는 청소년의 경우 관계성 만족과 자율성 욕구가 모두 충족 될 때 심리적 안녕감이 높으며, 특히 우리나라 청소년의 심리적 인 안녕감은 관계성 만족이 높을 때 자율성 만족으로 인한 긍 정적인 영향이 극대화 될 수 있다는 것을 시사한다.

연구문제 2 인 청소년의 자율성 및 관계성 만족이 심리적 안 녕감에 미치는 영향이 개인주의-집합주의 가치관에 따라 달 라지는지 각 집단을 대상으로 회귀분석을 실시하였다. 그 결 과, 개인주의 가치관 집단 청소년은 관계성 만족과 자율성 만 족의 주 효과가 나타났으며, 자율성 만족과 관계성 만족의 상 호작용효과는 나타나지 않았다. 따라서 개인주의 성향이 높 은 청소년의 경우는 SDT 관점에서 본 대부분의 서구연구 결 과들과 마찬가지로 자율성 만족과 관계성 만족이 그들의 심리 적인 안녕감에 각각 중요한 영향을 미치는 변인임을 알 수 있 다. 흥미로운 점은 한국과 미국대학생을 비교한 국외연구(예: Sheldon et al., 2001)나 국내 청소년을 대상으로 한 연구결과들 (예: E. J. Kim, 2007)과 마찬가지로 관계성 만족이 자율성 만족 보다 좀 더 큰 영향을 미치고 있다는 점이다. 따라서 청소년기 는 자율성 충족이 증대되는 시기이지만, 개인적으로는 개인주 의 성향이 강한 청소년이라 할지라도 한국사회의 전통적인 가 치관의 중요한 부분을 차지하고 있는 내재적 가치관인 상호 의존적(interdependent) 관계성 만족은 이들의 심리적 안녕감 
에 중요한 영향을 미치는 것으로 해석된다. 반면, 집합주의 가 치관 집단 청소년의 경우 관계성 만족과 자율성 만족의 독립 적인 영향력 외에도 둘 간의 상호작용효과가 나타났다. 즉, 집 합주의 성향이 높은 청소년은 자율성 만족이 심리적 안녕감 에 미치는 긍정적인 영향은 관계성 만족이 높을 때에만 나타 났다. 반면에 관계성 만족이 낮을 때는 자율성 만족이 심리적 안녕감에 미치는 긍정적인 영향은 자율성 만족이 높고 낮음에 따라 거의 없었다.

가치관의 중재효과에 대한 본 연구 결과를 요약하면, 개인 주의 가치관 성향이나 집합주의 가치관 성향을 가진 청소년 의 경우 모두 관계성 만족과 자율성 만족은 심리적 안녕감에 독립적으로 정적인 영향을 미쳐, 우리나라 청소년은 가치관 에 상관없이 자율성과 관계성을 높게 지각할수록 심리적 안녕 감이 높다는 것을 알 수 있다. 그럼에도 불구하고 개인주의 가 치관 성향을 가진 청소년에 비해 집합주의 가치관 성향을 가 진 청소년은 특히 관계성 만족이 그들의 심리적 안녕감에 결 정적인 변인임을 알 수 있다. 이러한 결과는 문화적 가치관에 상관없이 자율성과 관계성의 욕구는 긍정적 발달을 위한 인간 의 기본 심리적 욕구로 작용한다는 기존 연구 결과와 일치한 다(Chirkov et al., 2003; Hahn \& Oishi, 2006). 또한 자율성 만족 과 안녕감 간의 관계에 관한 비교문화 연구에서 조화, 관계, 복 종 등의 가치를 강조하는 집합주의 문화권에서도 자율성 만 족은 안녕감과 정적인 관계가 있다고 밝힌 기존 연구(Lynch, 2010; Sheldon et al., 2001)와 맥을 같이 하는 결과라고 할 수 있 다. 반면, 이러한 결과는 개인주의 가치가 높게 평가하는 서구 문화권에서는 자율성을 지지받는 것이 개인의 적응 및 안녕감 에 이익을 주지만, 집합주의를 강조하는 문화권에서는 자율 성 지지가 오히려 부정적인 영향을 준다는 선행 연구(Rudy \& Grusec, 2001)와는 다르다. 이러한 선행연구에서의 불일치는 자율성에 대한 개념의 차이에 기인할 수 있다(Vanstennkistee et al., 2006). 본 연구에서는 자기결정이론을 바탕으로 자율성의 개념을 외부의 통제를 받지 않고 자발적으로 선택하고 결정하 는 것으로 정의하였다. 이에 반해, 비교문화적 입장을 반영한 대부분의 선행연구에서는 대체로 자율성을 독립, 타인과의 분 리, 개인화 등으로 개념화하기 때문에 차이가 나타난 것으로 풀이된다.

그러나 이러한 차이에도 불구하고 본 연구 결과는 인간의 기본 심리적 욕구로써의 자율성 만족과 관계성 만족은 문화적 가치관과 상관없이 개인의 심리적 안녕감 증진을 위해 필요한 보편적인 심리적 욕구라는 자기결정이론의 주장을 지지한다. 또한 집합주의 가치관 집단에서만 관계성 만족의 중재효과가
나타나 그 중요성이 확인된 본 연구 결과는 문화적 가치관에 따라 관계성의 욕구가 미치는 상대적 영향력이 다를 수 있음 을 시사한다. 특히 집합주의 가치관 성향의 청소년은 관계성 만족이 높을 때에만 자율성 만족의 효과가 나타나며, 자율성 만족 및 관계성 만족이 모두 높을 시 심리적 안녕감이 가장 높 다는 결과에서 이들의 심리적 안녕감 증진을 위해서는 관계성 욕구를 지지받을 수 있는 방법과 환경이 제공되어야 한다는 결론을 지을 수 있다.

본 연구에서의 결과나 결론은 연구 방법상의 제한점으로 인해 일반화에 주의를 요한다. 첫째, 본 연구는 수도권 및 광 역시에 거주하는 고등학생 청소년들만을 대상으로 하였기 때문에 앞으로 더 넓은 지역으로 연구대상의 범위를 확대하 여 연구결과를 확인할 필요가 있다. 둘째, 본 연구에서는 청 소년이 일반적인 관계로부터 지각하는 자율성 및 관계성 만 족을 측정하였으나, 지지 및 관계를 제공하는 대상이 누구인 지, 또는 청소년이 처한 상황이 어떤지에 따라 청소년의 적응 및 안녕감에 미치는 영향력이 다를 수 있다(Han \& Shin, 2009; Vansteenkiste et al., 2006; Veronneau et al, 2005). 따라서 추후 연 구에서는 청소년에게 영향을 주는 지지 대상이나 처한 상황을 고려하여 그 영향력을 탐색해 본다면, 청소년 상담 및 지도에 도움이 될 수 있는 자료로 활용될 수 있을 것이다.

이러한 제한점에도 불구하고 본 연구는 다음과 같은 의의 를 지닌다. 첫째, 최근 자기결정이론의 기본 심리적 욕구와 안 녕감과 관련된 변인 들 간의 관계를 살펴보는 연구가 국외를 중심으로 활발히 진행됨에도 불구하고, 국내에서 10 대 청소 년을 대상으로 한 연구는 드문 실정이다. 따라서 본 연구는 10 대 청소년들의 심리적 안녕감을 도모할 수 있는 관련 변인을 모색했다는 점에서 그 의의를 찾을 수 있다. 둘째, 같은 문화권 내에서도 개인의 문화적 가치관에 따라 심리적 안녕감에 대한 자율성과 관계성의 영향력이 다르게 나타날 수 있음에도 불구 하고, 지금까지의 선행연구는 국가 간 또는 문화집단(예: 개인 주의/집합주의) 간 비교연구가 주류를 이루어져왔다. 본 연구 는 같은 문화권에 있는 청소년을 개인주의 가치관 청소년과 집합주의 가치관 청소년으로 나누어 비교함으로써, 같은 문화 권 내에서도 개인의 문화적 가치관에 따라 기본 심리적 욕구 만족의 상대적 영향력이 다를 수 있다는 점을 밝혔다는 것에 그 의의가 있다. 


\section{Notes}

This article is a part of the first author's master's thesis submitted in 2012, and was presented as poster at the 2013 Biennial Meeting of the Society for Research in Child Development

\section{Conflict of Interest}

No potential conflict of interest relevant to this article was reported.

\section{References}

\section{In English}

Aiken, L. S., \& West, S. G. (1991). Multiple regression: Testing and interpreting interactions. Thousand Oak, CA: Sage Publications.

Chirkov, V. I., \& Ryan, R. M. (2001). Parent and teacher autonomysupport in Russian and US adolescents: Common effects in well-being and academic motivation. Journal of CrossCultural Psychology, 32(5), 618-635. Retrieved from https://scr.hse.ru/data/2011/06/04/1212176229/Chirkov_ Ryan_2001.pdf

Chirkov, V. I., Ryan, R. M., Kim, Y., \& Kaplan, U. (2003). Differentiating autonomy from individualism and independence: A self-determination theory perspective on internalization of cultural orientations and well-being. Journal of Personality and Social Psychology, 84(1), 97-110. doi:10.1037/0022-3514.84.1.97

Cross, S. E., \& Gore, J. S. (2003). Cultural models of the self. In M. R, Leary \& J. P. Tangney (Eds.), Handbook of self and identity (pp. 536-564). New York: Guilford Press.

Deci, E. L., \& Ryan, R. M. (2000). The "what" and "why" of goal pursuits: Human needs and the self-determination of behavior. Psychological Inquiry, 11(4), 227-268. doi:10.1207/S15327965PLI1104_01

Deci, E. L., Ryan, R. M., Gagné, M., Leone, D. R., Usunov, J., \& Kornazheva, B. P. (2001). Need satisfaction, motivation, and well-being in the work organizations of a former Eastern bloc country: A cross-cultural study of self-determination. Personality and Social Psychology Bulletin, 27(8), 930-942. doi:10.1177/0146167201278002

Hahn, J., \& Oishi, S. (2006). Psychological needs and emotional well-being in older and younger Koreans and Americans.
Personality and Individual Differences, 40(4), 689-698. doi:10.1016/j.paid.2005.09.001

Joussemet, M., Landry, R. L., \& Koestner, R. (2008). A selfdetermination theory perspective on parenting. Canadian Psychology, 49(3), 194-200. doi:10.1037/a0012754

Kagitcibasi, C. (2005). Autonomy and relatedness in cultural context: Implications for self and family. Journal of Cross-Cultural Psychology, 36(4), 403-422. doi:10.1177/0022022105275959

Kitayama, S., \& Markus, H. R. (1998). Yin and Yang of the Japanese self: The cultural psychology of personality coherence. In D. Cervone \& Y. Shoda (Eds.), The coherence of personality: Social-cognitive bases of consistency, variability, and organization (pp. 242-302). New york: Guildford Press.

La Guardia, J. G., Ryan, R. M., Couchman, C. E., \& Deci, E. L. (2000). Within-person variation in security of attachment: A self-determination theory perspective on attachment, need fulfillment, and well-being. Journal of Personality and Social Psychology, 79(3), 367-384. doi: 10.1037/00223514.79.3.367

Levesuque, C., Zuehlke, A. N., Stanek, L. R., \& Ryan, R. M. (2004). Autonomy and competence in German and American university students: A comparative study based on self-determination theory. Journal of Educational Psychology, 96(1), 68-84. doi:10.1037/0022-0663.96.1.68

Lynch, M. (2010). Basic needs and well-being: A self-determination theory view. Retrieved from http://counsellingoutfitters. $\mathrm{com} /$ vistas/vistas10/Article_70.pdf

Markus, H. R., \& Kitayama, S. (2003). Models of agency: Sociocultural diversity in the construction of action. In M. B. V. Murphy-Berman \& J. J. Berman (Eds.), Crosscultural differences in perspectives on the self. volume 49 of the nebraska symposium on motivation (pp.1-57). Lincoln: University of Nebraska Press.

Oishi, S. (2000). Goals as cornerstones of subjective well-being: Linking individuals and cultures. In E. Diener \& E. M. Suh (Eds.), Culture and subjective well-being (pp.87-112). Cambridge: The MIT Press.

Petegem, S. V., Beyers, W., Vansteenkiste, M., \& Soenens, B. (2011). On the association between adolescent autonomy and psychosocial functioning: Examining decisional independence from a self-determination theory perspective. Developmental Psychology, 48(1), 76-88. doi:10.1037/ a0025307

Rudy, D., \& Grusec, J. E. (2001). Correlates of authoritarian parenting in individualist and collectivist cultures and implications for understanding the transmission of values. Journal of Cross-Cultural Psychology, 32, 202-212. doi:10.1177/0022022101032002007

Ryan, R. M., \& Deci, E. L. (2000). Self-determination theory and the facilitation of intrinsic motivation, social development, 
and well-being. American Psychologist, 55(1), 68-78. doi: 10.1037110003-066X.55.1.68

Ryan, R. M., \& Deci, E. L. (2002). Overview of self-determination theory: An organismic dialectical perspective. In E. L. Deci \& R. M. Ryan (Eds.), Handbook of self-determination research (pp. 3-33). Rochester, NY: The University of Rochester Press.

Ryff, C. D., \& Keyes, C .L. M. (1995). The structures of psychological well-being revisited. Journal of Personality and Social Psychology, 69(4), 719-727. Retrieved from http:// midus.wisc.edu/findings/pdfs/830.pdf

Sheldon, K. M., Eliot, A. E., Kim, Y., \& Kasser, T. (2001). What is satisfying about satisfying events? Testing 10 candidate psychological needs. Journal of Personality and Social Psychology, 80(2), 325-339. doi:10.1037//00223514.80.2.325

Soenens, B., \& Vansteekiste, M. (2005). Antecedents and outcomes of self-determination in 3 life domains: The role of parents' and teachers' autonomy support. Journal of Youth and Adolescence, 34(6), 589-604. doi:10.1007/s10964-0058948-y

Triandis, H. C. (1995). Individualism and collectivism. Boulder, CO: Westview Press.

Vansteekiste, M., Lens, W., Soenens, B., \& Luyckx, K. (2006). Autonomy and relatedness among Chinese sojourners and applicants: Conflictual or independent predictors of wellbeing and adjustment? Motivation \& Emotion, 30(4), 273282. doi:10.1007/s11031-006-9041-x

Veronneau, M. H., Koestner, R. F., \& Abela, J. R. Z. (2005). Intrinsic need satisfaction and well-being in children and adolescents: An application of the self-determination theory. Journal of Social and Clinical Psychology, 24(2), 280292. doi:10.1521/jscp.24.2.280.62277

\section{In Korean}

Ahn, D. H., Park, K. H., \& Jung, J. W. (2008). The relationship between autonomy support, basic needs, and psychological well-being. Korean Youth Research, 15(5), 315-338. Retrieved from http://www.riss.kr/link?id=A102952307

Cha, K.-H. (1999). Relationships between subjective well-being and idiocentrism-allocentrism of college students. Korean Institute for Youth Development, 30, 193-216. Retrieved from http://www.riss.kr/link?id=A30032190

Han, S., \& Shin, H. (2009). Effects of basic psychological needs satisfaction in parent-child relationship on subjective well-being in university students. The Korean Journal of Counseling and Psychotherapy, 21(2), 439-464. Retrieved from http://www.riss.kr/link?id=A100630555
Jeon, S. H., Sihn, M., \& Yoo, M. S. (2011). Analysis of the structural relationships among parental monitoring, selfdetermination, and happiness. Korean Journal of Play Therapy, 14(2), 73-87. Retrieved from http://www.riss.kr/ link?id=A82590442

Kang, S. H. (2010). The relationship of perceived attachment, depression, and psychological well-being to school adjustment in middle school students. The Secondary Education Research, 58(3), 1-29. Retrieved from http:// www.riss.kr/link?id=A82569653

Kim, A., \& Lee, M.-H. (2008). Structural relationships among adolescents' psychological need satisfaction, depressive tendency, and school adjustment in middle- and highschool. The Korean Journal of Educational Psychology, 22(2), 423441. Retrieved from http://www.riss.kr/link?id=A102750120

Kim, E. J. (2007). Effects of self-determination on college freshman's life satisfaction. The Korean Journal of Educational Psychology, 21(3), 539-555. Retrieved from http://www.riss. $\mathrm{kr} /$ link?id=A102750226

Lee, M., \& Kim, A. (2008) Development and construct validation of the basic psychological needs scale for Korean adolescents: Based on self-determination theory, Korean Journal of Social and Personality Psychology, 22(4), 157-174. Retrieved from http://www.riss.kr/link?id=A100629694

Lee, S. (2009). The effect of sense social connectedness and autonomy on college adjustment and subjective well-being among university students: Testing a mediation effect of interpersonal problems. The Korean Journal of School Psychology, 6(2), 229-248. Retrieved from http://www.riss. $\mathrm{kr} /$ link?id=A100633055

National Youth Policy Institute. (2010). NYPI 2010 adolescents statistics brief: Quality of life of Korean adolescent. Retrieved from http://www.nypi.re.kr/

Park, S. (2007). Mother's life satisfaction and parenting behavior as related to child social competence (Master's thesis). Retrieved from http://www.riss.kr/link?id=T10908723

Park, S. (2012). Relations between adolescent's emotion, individualism-collectivism cultural disposition and prosocial behavior (Doctoral dissertation). Retrieved from http:// www.riss.kr/link?id=T12648429

Shin, Y. J. (2011). Structural relationships among basic psychological needs satisfaction stress, and school adjustment (Master's thesis). Retrieved from http://www.riss.kr/ link?id=T12430634 


\section{KJCS}

\section{ORCID}

Seungbin Hong http://orcid.org/0000-0002-3167-0213

Seong Yeon Park http:/orcid.org//0000-0001-8762-7006
Received February 29, 2016

Revision received April 12, 2017

Accepted April 24, 2017 